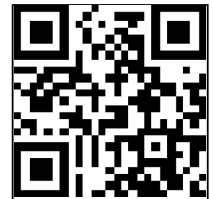

Editor's choice Scan to access more free content
- Additional material is published online only. To view please visit the journal online (http://dx.doi.org/10.1136/ bjsports-2014-093991).

For numbered affiliations see end of article.

\section{Correspondence to} Dr Margo Mountjoy; FINA c/o Michael G. DeGroote School of Medicine, McMaster University Waterloo Regional Campus, 10-B Victoria Street South, Kitchener, Ontario, Canada N2G 1C5; mmsportdoc@ mcmaster.ca

Accepted 26 September 2014 Published Online First 17 October 2014
CrossMark

To cite: Mountjoy $M$, Junge $A$, Benjamen $S$, et al. Br J Sports Med 2015:49:37-43.

\title{
Competing with injuries: injuries prior to and during the 15th FINA World Championships 2013 (aquatics)
}

Margo Mountjoy, ${ }_{1}^{1,2,3}$ Astrid Junge, ${ }^{4,5,6}$ Sarah Benjamen, ${ }^{7}$ Kevin Boyd, ${ }^{2,8}$ Mohamed Diop, ${ }^{2}$ David Gerrard, ${ }^{2,9}$ Cees-Rein van den Hoogenband, ${ }^{2}$ Saul Marks, ${ }^{2,10}$ Enrique Martinez-Ruiz, ${ }^{11}$ Jim Miller, ${ }^{2,12}$ Kyriakos Nanousis, ${ }^{2}$ Farhad Moradi Shahpar, ${ }^{2,13}$ Jose Veloso, ${ }^{2,14}$ William van Mechelen, ${ }^{15}$ Evert Verhagen ${ }^{15,16}$

\section{ABSTRACT}

Background Injury and illness surveillance is the foundation for the development of prevention strategies. Objective To examine injuries among the aquatic disciplines in the 4 weeks prior to and during the 2013 FINA World Championships.

Methods The study was comprised of two components: (1) a retrospective athlete survey recording injuries in the 4 weeks prior to the Championships and (2) a prospective recording of injuries and illnesses by the medical teams of the participating countries and the local host medical team.

Results One-third of the 1116 responding athletes reported an injury/physical complaint in the 4 weeks prior to the Championships. Significantly more women (36.7\%) than men $(28.6 \%)$ reported injuries. Divers reported the highest rate of injury/physical complaints (55.7\%). At the start of the Championships, $70 \%$ of injured respondents $(n=258)$ were still symptomatic; however, full participation was expected by $76 \%$. During the Championships, 186 new injuries were reported (8.3/100 registered athletes) with the highest injury incidence rate in water polo (15.3/100 registered athletes). The most common injured body part was the shoulder (21\%). A total of 199 illnesses were reported during the Championships (9.0/100 registered athletes) with the most common diagnosis of illness being gastrointestinal infection. Environmental exposure (allergy, otitis and jellyfish stings) was responsible for $27 \%$ of all illnesses in open water swimming.

Conclusions Injuries pose a significant health risk for elite aquatic athletes. A prospective study would improve understanding of out-of-competition injuries. Future injury and illness surveillance at FINA World Championships is required to direct and measure the impact of prevention strategies.

\section{INTRODUCTION}

From the recreational to the elite level, aquatic sports are universally popular around the world. In 2013, FINA, the international federation governing aquatic sports, held its 15 th World Championships in Barcelona, Spain involving 2223 athletes from 177 countries competing in 68 events in the disciplines of swimming, water polo, diving, synchronised swimming and open water swimming. The $30 \mathrm{~m}$ platform diving event was introduced at these Championships.

FINA implemented its first injury surveillance at its World Championships in Rome 2009. ${ }^{1}$ Water polo was included in the injury surveillance study of team sports during the 2004 Olympic Games, ${ }^{2}$ and all aquatic disciplines were surveyed in the $2008^{3}$ and $2012^{4}$ Olympic Games. Illness surveillance was implemented in the FINA World Championships $2009^{1}$ and in the 2012 Olympic Games. ${ }^{4}$

Results from the 2009 survey revealed that overuse $(37.5 \%)$ was the most common mechanism for injury. ${ }^{1}$ Similarly, at the 2012 Olympic Games, diving had the highest incidence of overuse injuries (73\%) compared to all sports. ${ }^{4}$ The injury registration methodology utilised in the FINA and IOC injury surveillance studies, however, only records newly acquired injuries without capturing injuries incurred during training. Athletes may continue to train and compete despite injury and other physical complaints, especially in the time period before major competitions.

To facilitate the development of future prevention strategies for aquatic athletes, this study (1) assessed the presence and characteristics of injuries and physical complaints in the 4 weeks prior to and at the start of the FINA World Championships 2013 and (2) described the incidence and nature of new-onset injuries and illnesses incurred during competition.

\section{METHODS}

The study was implemented at the 2013 FINA World Championships in Barcelona, Spain. The Championships consisted of competitions in six disciplines, and the study population included all registered athletes. Informed consent was obtained via the athlete entry form. Ethical approval was obtained from the University of Oslo, School of Medicine Ethical Committee and the Collegi Oficial de Metges de Barcelona.

The study involved two components: (1) a retrospective questionnaire on injuries and physical complaints in the 4 weeks prior to and at the start of the Championships to be completed by the athletes and (2) a prospective survey of new-onset injuries and illnesses reported by the local organising committee (LOC) and national medical teams.

\section{Retrospective questionnaire on prior complaints}

A retrospective survey on athletes' injuries and physical complaints during the 4 weeks prior to the Championships was developed to capture the presence, number, location and duration of injuries and 
physical complaints, as well as their effect on training and competition performance (see online supplementary appendix 1). It included a modified, extended version of the four questions of the Oslo Sports Trauma Research Centre questionnaire. ${ }^{5}$

Athletes were asked to report all injuries or other physical complaints that they experienced in the 4 weeks prior to the Championships, regardless of the consequences for participation in normal training and/or competition. These outcomes are subsequently referred to as 'prior complaints'. The questionnaire was available in English, French and Spanish. Athletes received the questionnaires from their team physician, and returned them prior to or during the event either in person to a member of the research team or via secure locked drop boxes located in the training and competition venues and the FINA office.

\section{Prospective survey on new-onset injuries and illnesses}

The prospective injury and illness surveillance was based on the IOC protocol, ${ }^{6}$ previously implemented at the 2009 FINA World Championships. ${ }^{1}$ The injury and illness report form was available in English, French, Spanish, Italian and Russian. Daily reporting by the team physician and LOC medical staff was accomplished electronically or via a secured drop box.

\section{Implementation}

The purpose and logistics of the study were communicated electronically to the National Federations and team physicians registered in the FINA database 3 months prior to the Championships. The FINA Bureau Sports Medicine Liaison (MM) undertook a pre-event site visit to train the LOC medical staff. Prior to the opening ceremony and prior to the start of the second week, an educational session was held for all national federation and LOC physicians. The study logistics were also presented at the technical meetings of each discipline.

During the competitions, members of the FINA Study Group attended every competition event to encourage reporting compliance. Injury and illness data gathered by the LOC from the training/competition sites, medical clinics, athlete hotels and the Championship hospital network were obtained daily from the Chief Medical Officer's utilisation report database. There was a daily review of the quality of the data and an analysis of reporting compliance. The medical staff of non-compliant countries were subsequently contacted to encourage reporting. Duplication of data entries of injuries and illnesses was resolved by the consensus of $\mathrm{MM}$ and $\mathrm{AJ}$.

\section{Definitions and calculation of exposure data and incidences}

A discipline was defined as one of the six aquatic sports (swimming, diving, high diving, open water swimming, synchronised swimming and water polo). An event was defined as a competition activity if medals were awarded (eg, 1, 3 and $10 \mathrm{~m}$ diving). The number of competing athletes in the individual events was calculated from the official start lists. ${ }^{7}$ Athletes starting in different events were included for each event. Athletes who did not finish or were disqualified were included as competing athletes.

The number of starts was calculated using the official results list. $^{7}$ For the individual sports, all results (including disqualifications and athletes who did not finish) were each included as a start; for example, an athlete competing in the heats, semifinals and finals of a swimming event was counted as three starts. Athletes who started in different disciplines (eg, swimming and open water swimming) were counted for each discipline. For swimming relays, synchronised swimming events, synchronised diving and open water swimming team events, the number of starts was calculated by multiplying the number

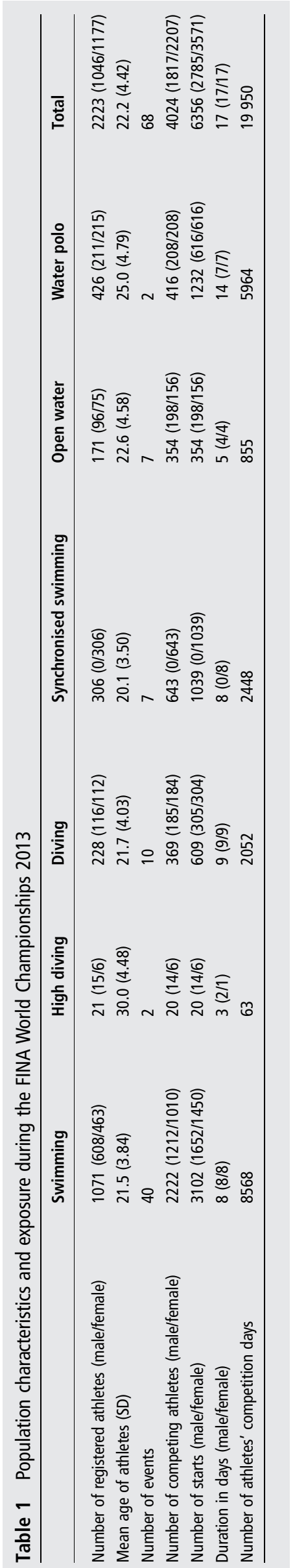




\begin{tabular}{|c|c|c|c|c|c|c|c|}
\hline & Swimming & High diving & Diving & $\begin{array}{l}\text { Synchronised } \\
\text { swimming }\end{array}$ & Open water & Water polo & Total* \\
\hline Number of responding athletes (\# male/female) & $464(250 / 214)$ & $17(14 / 3)$ & $88(38 / 50)$ & $122(0 / 122)$ & $87(45 / 42)$ & $329(153 / 176)$ & $1116(500 / 610)$ \\
\hline Percentage of responders (male/female) & $\begin{array}{l}43.3(41.1 / \\
46.2)\end{array}$ & $\begin{array}{l}81.0(93.3 / \\
50.0)\end{array}$ & $\begin{array}{l}38.6(32.8 / \\
44.6)\end{array}$ & $39.9(0 / 39.9)$ & $\begin{array}{l}50.9(46.9 / \\
56.0)\end{array}$ & $\begin{array}{l}77.2(72.5 / \\
81.9)\end{array}$ & $\begin{array}{l}50.2(47.8 / \\
51.8)\end{array}$ \\
\hline $\begin{array}{l}\text { Percentage of responders with prior complaint (male/ } \\
\text { female) }\end{array}$ & $\begin{array}{l}23.5(21.6 / \\
25.7)\end{array}$ & $23.5(28.6 / 0)$ & $\begin{array}{l}55.7(57.9 / \\
54.0)\end{array}$ & $42.6(0 / 42.6)$ & $\begin{array}{l}17.4(15.6 / \\
19.0)\end{array}$ & $\begin{array}{l}41.9(36.6 / \\
46.6)\end{array}$ & $\begin{array}{l}33.0(28.6 / \\
36.7)\end{array}$ \\
\hline Mean age of responders (SD) & $21.9(3.84)$ & $29.3(4.82)$ & $21.4(3.87)$ & $19.7(3.27)$ & $22.1(4.77)$ & $24.5(4.23)$ & $22.5(4.35)$ \\
\hline Mean age of injured athletes (SD) & $22.1(4.08)$ & $29.3(5.74)$ & $20.9(3.69)$ & $18.9(3.06)$ & $23.8(4.51)$ & $24.2(3.85)$ & $22.4(4.31)$ \\
\hline \multicolumn{8}{|l|}{ Participation in previous 4 weeks } \\
\hline Full $(\%)$ & 84.0 & 75.0 & 62.3 & 78.4 & 80.0 & 72.9 & 76.0 \\
\hline Reduced (\%) & 14.2 & 0 & 34.7 & 19.6 & 20.0 & 26.3 & 22.3 \\
\hline Unable (\%) & 1.8 & 25.0 & 3.0 & 2.0 & 0 & 0.8 & 1.7 \\
\hline Average number of body parts (SD) & $1.28(0.80)$ & $1.25(0.50)$ & $1.17(0.52)$ & $1.65(0.93)$ & $1.53(0.92)$ & $1.43(0.85)$ & $1.38(0.82)$ \\
\hline \multicolumn{8}{|l|}{ Days of limited performance in previous 4 weeks } \\
\hline $0(\%)$ & 15.6 & 25.0 & 20.4 & 18.4 & 50.0 & 13.3 & 17.0 \\
\hline $1-3(\%)$ & 18.8 & - & 13.0 & 20.4 & - & 17.2 & 16.7 \\
\hline $4-7(\%)$ & 38.5 & 50.0 & 26.1 & 22.4 & 8.3 & 26.6 & 29.2 \\
\hline $8-14(\%)$ & 14.6 & - & 15.0 & 24.5 & 8.3 & 14.8 & 15.8 \\
\hline $15-27(\%)$ & 7.3 & - & 15.0 & 6.1 & 25.0 & 13.3 & 11.0 \\
\hline $28-30(\%)$ & 5.2 & 25.0 & 10.5 & 8.2 & 8.3 & 14.8 & 10.4 \\
\hline Median days (IQR)* & $5.0(8.0)$ & $6.0(8.5)$ & $5.5(11)$ & $6.0(11)$ & $2.0(20)$ & $7.0(12)$ & $6.0(11.5)$ \\
\hline \multicolumn{8}{|l|}{ Symptoms at start of competition } \\
\hline None (\%) & 34.7 & - & 20.8 & 26.9 & 57.0 & 31.6 & 30.9 \\
\hline Minor (\%) & 48.7 & 50.0 & 54.2 & 42.4 & 21.5 & 48.6 & 47.5 \\
\hline Moderate (\%) & 15.8 & - & 20.8 & 26.9 & 14.4 & 16.9 & 18.3 \\
\hline Major (\%) & 0.8 & 25.0 & 2.1 & 1.9 & 7.1 & 2.9 & 2.5 \\
\hline No participation (\%) & - & 25.0 & 2.1 & 1.9 & - & - & 0.8 \\
\hline \multicolumn{8}{|l|}{ Performance affected at start of competition } \\
\hline Not at all (\%) & 55.5 & 25.0 & 43.8 & 50.0 & 64.3 & 55.9 & 53.4 \\
\hline Minor (\%) & 37.6 & - & 33.4 & 40.4 & 7.1 & 31.6 & 33.4 \\
\hline Moderate (\%) & 6.9 & 25.0 & 12.5 & 5.8 & 21.5 & 8.1 & 8.7 \\
\hline Major (\%) & - & 25.0 & 8.3 & - & 7.1 & 4.4 & 3.4 \\
\hline No participation (\%) & - & 25.0 & 2.0 & 3.8 & - & - & 1.1 \\
\hline
\end{tabular}


of athletes on a team by the number of entries. For water polo, the number of starts was calculated as the number of player-matches $(2$ teams $\times 7$ players $\times$ the number of matches played).

The number of athlete competition days was calculated by multiplying the number of registered athletes in each discipline by the total number of days of competition for the respective discipline as per the official competition schedule.

\section{Calculation of incidences and data analysis}

Incidence rates were calculated as the number of injuries or illnesses per 100 registered or competing athletes in the respective discipline. $^{6}$

Data were processed using Excel and SPSS. The statistical methods applied were descriptive statistics, cross tabulations, $\chi^{2}$ and $\mathrm{t}$ tests. For incidence rates, 95\% CIs were calculated. Statistical significance was accepted at a p value of 0.05 or lower.

\section{RESULTS}

\section{Number and exposure of athletes}

A total of 2223 athletes from 177 countries registered for the 2013 FINA World Championships that resulted in almost 20000 athlete competition days. As most athletes, except high divers and water polo players, competed in more than one event, the number of competing athletes was almost double the number of registered athletes. Overall, more female (53\%) than male athletes (47\%) participated. The athletes' ages range from 12 to 41 years with an average of 22.2 years (SD 4.42). For further details on the characteristics of the athletes and their exposure see table 1 .

\section{Retrospective questionnaire on prior complaints}

A total of 1116 athletes (610 women and 500 men) completed the retrospective survey of prior complaints, representing an overall response rate of $50.2 \%$, varying by discipline from $38.6 \%$ (diving) to $81 \%$ (high diving). Survey responders and nonresponders were similar in age and gender, but were statistically different with regard to distribution by discipline (table 2).

Approximately one-third of the responding athletes $(n=368$; $33 \%$ ) reported a physical complaint in the 4 weeks prior to the Championships. The duration of prior complaints varied from 7 days to 10 years with a median duration of 85.3 days. The mean age of athletes with and without prior complaints was similar. Significantly more females $(n=224 ; 36.7 \%)$ than males $(n=143 ; 28.6 \%)$ reported prior complaints $\left(\chi^{2}=7.83\right.$; $\mathrm{p}<0.005$ ), and the proportion of athletes with a prior complaint differed with statistical significance between disciplines $\left(\chi^{2}=68.2 ; p<0.001\right)$. More than half of the divers $(55.7 \%)$ reported prior complaints compared to only $17.4 \%$ of open water swimmers.

More than three quarters of athletes with prior complaints $(\mathrm{n}=273 ; 76 \%)$ reported full participation in training in the 4 weeks leading up to the Championships, but only $57(17 \%)$ reported that their performance had not been affected due to injury. The median number of days of limited sport participation was 6 . High diving and water polo had the greatest number of days of limited performance.

At the start of the Championships, less than one-third of athletes with prior complaints $(30.9 \%)$ reported no current symptoms, $47.5 \%$ minor symptoms, $18.3 \%$ moderate symptoms and $2.5 \%$ severe symptoms. More than half $(53.4 \%)$ reported no effect on performance from their prior complaints at the beginning of the Championships. In contrast, four athletes were unable to participate in the Championships and $1.4 \%$, despite being severely affected, still competed.

\section{Prospective survey on new-onset injuries and illnesses during the Championships}

The medical staff from $55(31.1 \%)$ countries submitted 587 injury and illness report forms covering a total of 1571 athletes

Table 3 Number and incidence $(95 \% \mathrm{Cl})$ of injuries and illnesses during the FINA World Championships 2013

\begin{tabular}{|c|c|c|c|c|c|c|c|}
\hline & Swimming & High diving & Diving & Synchronised swimming & Open water & Water polo & Total $(95 \% \mathrm{Cl})^{*} \dagger$ \\
\hline All injuries (male/female) & $65(31 / 34)$ & $1(1 /-)$ & $26(10 / 16)$ & $5(-15)$ & $20(11 / 9)$ & $65(33 / 32)$ & $186(88 / 98)$ \\
\hline Per 100 registered athletes & 6.1 & 4.8 & 11.4 & 1.6 & 11.7 & 15.3 & $8.3(1.19)$ \\
\hline Per 100 athletes" competition days & 0.7 & 1.5 & 1.3 & 0.2 & 2.3 & 1.1 & 0.5 \\
\hline Training injuries & 46 & 0 & 12 & 1 & 4 & 18 & 81 \\
\hline Per 100 registered athletes & 4.3 & 0 & 5.3 & 0.3 & 2.3 & 4.2 & $3.6(0.78)$ \\
\hline Competition injuries & 16 & 1 & 14 & 4 & 16 & 47 & 98 \\
\hline Per 100 competing athletes & 0.7 & 5.0 & 3.8 & 0.6 & 4.5 & 11.3 & $2.4(0.48)$ \\
\hline Per 100 starts & 0.5 & 5.0 & 2.3 & 0.4 & 4.5 & 3.8 & $1.5(0.3)$ \\
\hline Time-loss injuries (male/female) & $12(2 / 10)$ & 0 & $7(2 / 5)$ & 0 & $2(1 / 1)$ & $11(9 / 2)$ & $32(14 / 18)$ \\
\hline Per 100 registered athletes & 1.1 & 0 & 3.1 & 0 & 1.2 & 2.6 & $1.4(0.49)$ \\
\hline Time-loss training injuries & 8 & 0 & 4 & 0 & 0 & 4 & 16 \\
\hline Per 100 registered athletes & 0.75 & 0 & 1.75 & 0 & 0 & 0.94 & $0.72(0.35)$ \\
\hline Time-loss competition injuries & 4 & 0 & 3 & 0 & 2 & 7 & 16 \\
\hline Per 100 competing athletes & 0.18 & 0 & 0.81 & 0 & 0.56 & 1.68 & $0.40(0.2)$ \\
\hline Per 100 starts & 0.1 & 0 & 0.5 & 0 & 0.6 & 0.6 & 0.3 \\
\hline All illnesses (male/female) & $95(51 / 44)$ & 0 & $9(6 / 3)$ & $23(-123)$ & $37(21 / 16)$ & $35(14 / 21)$ & $199(92 / 107)$ \\
\hline Per 100 registered athletes & 8.9 & 0 & 3.9 & 7.5 & 21.6 & 8.2 & $9.0(1.25)$ \\
\hline Per 100 athletes" competition days & 1.1 & 0 & 0.4 & 0.9 & 4.3 & 0.6 & 0.5 \\
\hline Time-loss illnesses (male/female) & $8(4 / 4)$ & 0 & $3(2 / 1)$ & $2(-12)$ & $2(1 / 1)$ & $10(5 / 5)$ & $25(12 / 13)$ \\
\hline Per 100 registered athletes & 0.75 & 0 & 1.3 & 0.7 & 1.1 & 2.3 & $1.1(0.43)$ \\
\hline Per 100 athletes' competition days & 0.1 & 0 & 0.1 & 0.1 & 0.2 & 0.2 & 0.1 \\
\hline
\end{tabular}


(70.7\%; table 3). A total of 186 injuries were reported, representing an incidence of $8.3 / 100$ registered athletes $(95 \% \mathrm{CI}$ \pm 1.19 ). The highest injury incidence was observed in water polo, followed by open water swimming and diving, and the lowest incidence was seen in synchronised swimming. The incidence of injuries was higher in training $(3.61 ; 95 \%$ CI \pm 0.78$)$ than in competition $(2.4 ; 95 \% \mathrm{CI} \pm 0.48)$. No other differences were found. Thirty-two injuries (17\%) were reported to result in time loss, equivalent to an incidence of 1.4/100 athletes (95\% CI \pm 0.49 ). Information on time loss was missing for 58 $(31.2 \%)$ injuries. The rate of time-loss injuries was lower in male athletes $(1.34 ; 95 \% \mathrm{CI} \pm 0.7)$ than in female athletes $(1.53 ; 95 \%$ CI \pm 0$)$.

The most common injured body part was the shoulder $(n=39 ; 21 \%$; figure 1$)$. Almost half $(49 \%)$ of the shoulder injuries and two-thirds of the time-loss shoulder injuries were reported in swimming. Water polo was responsible for

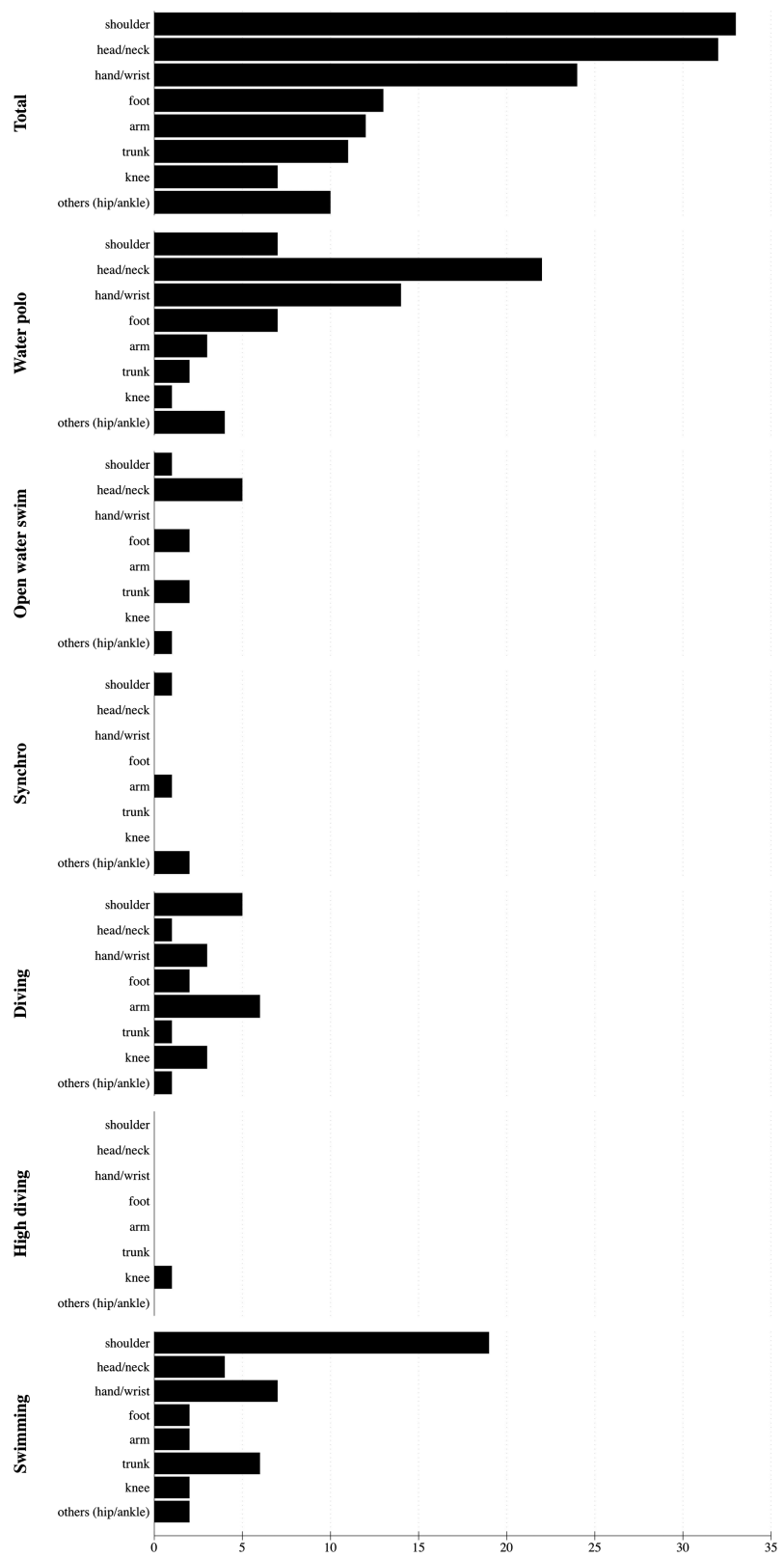

Figure 1 Injury location for new-onset injuries during the FINA World Championships 2013. two-thirds $(n=23)$ of all injuries to the head/neck. The most common injury type was contusion $(n=38 ; 20.4 \%)$, and the most frequent injury type was tendinosis of the shoulder $(n=17)$. The most common cause of injury was contact with another athlete $(n=46 ; 24.7 \%)$. Eight per cent of the reported injuries resulted in time loss of 1-2 weeks duration, and onequarter of all time-loss injuries were to the shoulder $(n=28)$. Data on time loss were missing in 53 (28\%) cases.

A total of 199 illnesses were reported during the Championships, resulting in an incidence of 9/100 registered athletes $(95 \% \mathrm{CI} \pm 1.25)$. There was no significant statistical difference between the number of illnesses reported in male (8.8; $95 \% \mathrm{CI} \pm 1.8)$ and female $(9.1 ; 95 \% \mathrm{CI} \pm 1.72)$ athletes. The highest rate of illness was reported in open water swimmers while no illnesses were reported in high divers (table 3). The most common diagnosis of illness was gastrointestinal infection, with environmental exposure resulting in allergic reactions, otitis and jellyfish stings in open water swimming accounting for $27 \%$ of all reported illnesses (figure 2). Twenty-five illnesses were reported to result in time loss, resulting in a rate of 1.1 (95\% CI \pm 0.43$)$ time-loss injuries per 100 registered athletes. Data on time loss were missing in $64(32 \%)$ cases. The highest rate of time-loss illnesses was observed in water polo.

\section{DISCUSSION}

Accurate injury surveillance is a fundamental component of effective risk management in sport. ${ }^{8-11}$ Despite the fact that out-of-competition prospective cohort studies are recommended to monitor injury patterns and risk, ${ }^{12-15}$ no studies of this type have been undertaken in aquatic sport disciplines. Two studies, one prospective study monitoring shoulder pain in Australian swimmers $^{16}$ and one descriptive retrospective epidemiological study ${ }^{17}$ in NCAA swimming, have been published.

\section{Retrospective questionnaire of prior complaints}

The retrospective component of this study is the first to evaluate the presence of out-of-competition injuries in international, elite aquatic athletes. Despite employing a narrow recall period of 4 weeks and a research population comprising only elite athletes, limitations to the accuracy of the retrospective survey exist with a potential for underestimation of injuries related to a potential recall bias. ${ }^{18} 19$ The more severe injuries of athletes who are subsequently unable to qualify for the FINA World Championships were not captured in this study. As such, the injury rates reported in this study are most likely an underestimation of the actual injury rates in elite aquatic athletes. In contrast, a strength of this survey was the recording of athlete symptoms rather than diagnoses, which allowed for greater capture of performance affecting physical complaints by bypassing the potential reporting bias of third party recorders who may interpret differently a recordable problem. This approach provided a more accurate interpretation of the effect that physical complaints may have on athletic performance. ${ }^{13} 14$

The survey responses demonstrated that almost a third of all athletes reported complaints, with $70 \%$ of them reporting prior complaints symptomatic at the commencement of the Championships. Despite these findings, the majority still participated in training, stating that their athletic performance was affected by their prior complaint at the start of the competition. This finding is consistent with the literature outlining that athletes across sport disciplines continue to train despite injury ${ }^{13}$ and demonstrates the need for interventions to address the prevention of non-time-loss injuries. Further research in aquatic 




Figure 2 Diagnosis of illnesses during the FINA World Championships 2013.

sports is required to determine whether symptomatic athletes are more vulnerable as previous injury is a known risk factor for injury. ${ }^{9}$ To achieve this end, prospective out-of-competition surveillance together with the standard in-competition protocol is recommended.

\section{Prospective survey on new-onset injuries}

The incidence of all and of time-loss injuries during the 2013 FINA World Championships was significantly higher than in 2009. ${ }^{1}$ This trend may be due to an increasingly tougher competition or to a busier competition calendar with a consequent decreased recovery period and a subsequent increased injury risk. It may also be attributed to the improved familiarity of team physicians with the injury surveillance system since a higher response rate was achieved in 2013 compared to the
FINA World Championships 2009. ${ }^{1}$ A similar trend was observed in the Olympic Games. ${ }^{3} 420$ Ongoing injury surveillance is required to decrease this reporting bias.

Consistent with previous published research, ${ }^{1} \quad 16 \quad 21-25$ the shoulder was the most commonly injured body part in aquatic sports. Despite the various theories of risk factors and injury mechanisms, ${ }^{162526}$ shoulder injury prevention programmes for aquatic sports have not been validated in the scientific literature. The findings of the present study illustrate the need for a validated shoulder injury prevention programme in the aquatic disciplines.

In the current study, the head and neck regions were the second most commonly reported injury locations. This unexpected finding was influenced by water polo, which reported more than $60 \%$ of all head and neck injuries. Water polo data also reflected the highest injury risk of all the aquatic disciplines with a higher number of head and neck injuries reported than shoulder injuries. A pragmatic approach to injury prevention in water polo would include a review of the current rules, de-emphasising contact, highlighting fair play and supporting the capacity of referees to sanction. These measures have been implemented in team sports such as football and rugby. ${ }^{27-32}$

\section{Prospective survey on illnesses}

Statistically significantly more illnesses were reported during the 2013 FINA World Championships than in 2009 (7.1/100 athletes; 95\% CI 1.03). ${ }^{1}$ This could have been influenced by the environmental risk variability between Barcelona (2013) and Rome (2009), and also as a result of the improved athlete healthcare provision and improved reporting quality. Consistent with other sports, infection was the leading cause of illness. ${ }^{4} 20$ 33-36 However, less upper respiratory infections were reported in $2013(n=36 ; 18 \%)$ than in $2009^{1}$ $(\mathrm{n}=91 ; 50.3 \%)$, possibly attributed to the presence of hand sterilising stations on site and the education of athletes on personal hygiene. ${ }^{37}$

Of particular concern was the reported frequency of otitis in all athletes ( $15 \%$ of all illnesses) and jellyfish stings in open water swimmers (38\% of illnesses in open water swimmers). These results demonstrate the need for the implementation of targeted preventive measures. The environmental risk posed by jellyfish warrants a closer evaluation of open water venues to develop risk reduction measures and the provision of appropriate medication for the treatment of potential anaphylactic emergencies.

\section{CONCLUSION}

This study demonstrates the need to investigate out-of-competition (training) injury patterns in aquatic sports through prospective injury surveillance in aquatic sports. In-competition injury and illness surveillance should continue to gain further insight into trends and to evaluate the efficacy of prevention interventions. While the disciplines of swimming, diving and synchronised swimming have low injury rates relative to other sports, water polo has a uniquely higher propensity for injury distinctively affecting the head, neck and shoulder. Implementation of prevention interventions should target the discipline of water polo, shoulder and head injuries, as well as aquatic-specific illnesses such as jellyfish stings and otitis. 


\section{What are the new findings?}

- One-third of all participating athletes reported having suffered physical complaints/injuries in the 4 weeks prior to the 2013 FINA World Championships.

- Diving and water polo had the highest incidence of physical complaints/injuries in the 4 weeks prior to the Championships relative to the other aquatic disciplines.

- Female aquatic athletes had a higher rate of physical complaints/injury than male aquatic athletes in the 4 weeks prior to the Championships.

- The incidence of new-onset injuries during the FINA World Championships was $8.3 \%$ with the highest incidence in water polo; and the illness incidence was $9 \%$ with the highest incidence in open water swimming.

- The most common injuries were contusions of the head and overuse injuries of the shoulder, and the most common illnesses were gastrointestinal and respiratory infections.

- How might it impact on clinical practice in the near future?

- Injury surveillance programmes in all aquatic disciplines should expand to capture data during the training season specifically in the time period leading up to a major competition.

- Prevention interventions should be developed to focus on injuries suffered during the out-of-competition (training) period.

- An analysis of the water polo rules should be implemented to address the injury patterns unique to this aquatic discipline.

- Injury prevention strategies in all aquatic disciplines should target shoulder and head injuries.

- Evaluation of environment factors in open water swimming is required.

\author{
Author affiliations \\ ${ }^{1}$ Department of Family Medicine, Michael G. DeGroote School of Medicine, \\ McMaster University, Hamilton, Canada \\ ${ }^{2}$ Fédération Internationale de Natation (FINA), Lausanne, Switzerland \\ ${ }^{3}$ International Olympic Committee (IOC), Lausanne, Switzerland \\ ${ }^{4}$ Fédération Internationale de Football Association (FIFA) Medical Assessment and \\ Research Centre (F-MARC), Zürich, Switzerland \\ ${ }^{5}$ Schulthess Klinik, Zürich, Switzerland \\ ${ }^{6}$ Hamburg Medical School (MSH), Germany \\ ${ }^{7}$ University of Southampton, Southampton, Great Britain \\ ${ }^{8}$ University Hospitals of Leicester NHS Trust, Leicester, Great Britain \\ ${ }^{9}$ Medicine Department, Dunedin School of Medicine, University of Otago, Dunedin, \\ New Zealand \\ ${ }^{10}$ Department of Psychiatry, University of Toronto, Toronto, Canada \\ ${ }^{11}$ Catholic University of San Antonio, Murcia, Spain \\ ${ }^{12}$ Medicine Department, University of Virginia, Charlottesville, and Virginia \\ Commonwealth University, Richmond, Virginia, USA \\ ${ }^{13}$ Department of Sport Medicine, Faculty of Physical Education and Sports Sciences, \\ University of Isfahan, Isfahan, Iran \\ ${ }^{14}$ Faculty of Biological Sciences, Catholic University of Uruguay, Montevideo, \\ Uruguay \\ ${ }^{15}$ Department of Public and Occupational Health, EMGO+ Institute for Health and \\ Care Research, VU University Medical Center, Amsterdam, The Netherlands \\ ${ }^{16}$ Australian Centre for Research into Injury in Sport and its Prevention (ACRISP), \\ Federation University Australia, SMB Campus, Ballarat, Victoria, Australia
}

Acknowledgements The authors highly appreciate the co-operation of all team physicians and medical staff of the FINA World Championships 2013 who volunteered their time to collect the data for this project. They thank Dr Nuria Torres, chief medical officer of BCN2013 for her co-operation in providing the medical data from the host medical clinics and venues and Dr Kathrin Steffen for her assistance with obtaining Ethics Committee approval from the University of Oslo. The authors also gratefully acknowledge FINA for its support and funding of the study.
Contributors MM substantially contributed to conception and design, data collection, interpretation of results, drafting and revising the manuscript and final version to be published. AJ substantially contributed to conception and design, development of the questionnaire and data collection methods, data analysis and interpretation of results, drafting and revising the manuscript, and final approval of the version to be published. SB, JV, KB, MD, C-RvdH, SM, EM-R, KN, FMS substantially contributed to acquisition of the data and final approval of the manuscript to be published. DG contributed to acquisition of the data, revising the manuscript and final approval of the manuscript to be published. JM contributed to acquisition of the data and final approval of the version to be published. WvM contributed to the manuscript and final approval of the version to be published. EV contributed to data collection, revising the manuscript and final approval of the version to be published.

\section{Competing interests None.}

Ethics approval University of Oslo, School of Medicine Ethical Committee+Collegi Oficial de Metges de Barcelona.

Provenance and peer review Not commissioned; externally peer reviewed.

\section{REFERENCES}

1 Mountjoy M, Junge A, Alonso JM, et al. Sports injuries \& illnesses in the 2009 FINA World Aquatic Championships. Br J Sports Med 2010;44:522-7.

2 Junge $A$, Langevoort $G$, Pipe $A$, et al. Injuries in team sport tournaments during the 2004 Olympic Games. Am J Sports Med 2006;34:565-76.

3 Junge A, Engebretsen L, Mountjoy M, et al. Sports injuries during the Summer Olympic Games 2008. Am J Sports Med 2009;37:2165-72.

4 Engebretsen L, Soligard T, Steffen K, et al. Sports injuries and illnesses during the London Summer Olympic Games 2012. Br J Sports Med 2013;0:1-8.

5 Clarsen B, Myklebust G, Bahr R. Development and validation of a new method for the registration of overuse injuries in sports injury epidemiology. $\mathrm{Br} / \mathrm{Sports} \mathrm{Med}$ 2013;47:495-502.

6 Junge A, Engebretsen L, Alonso JM, et al. Injury surveillance in multi-sport events -the IOC approach. Br J Sports Med 2008:42:413-21.

7 Omega Results. http://www.omegatiming.com/Sport?sport=AQ. Retrieved 7 December 2013

8 Fuller C, Drawer S. The application of risk management in sport. Sports Med 2004;34:349-56.

9 Fuller C. Managing the risk of injury in sport. Clin I Sport Med 2007:17:182-7.

10 Rogge J. An ounce of prevention? Br J Sports Med 2009;43:627.

11 Steffen K, Soligard T, Engebretsen L. Health protection of the Olympic athlete. $\mathrm{Br} J$ Sports Med 2012;46:466-70

12 Fuller C, Bahr R, Dick R, et al. A framework for recording recurrences, reinjuries, and exacerbations in injury surveillance. Clin I Sport Med 2007;17:197-200.

13 Bahr R. No injuries, but plenty of pain? On the methodology for recording overuse symptoms in sports. Br J Sports Med 2009;43:966-72.

14 Clarsen B, Ronsen O, Myklebust G, et al. The Oslo Sports Trauma Research Center Questionnaire on Health Problems: a new approach to prospective monitoring of illness and injury in elite athletes. Br I Sports Med 2014:48:754-60

15 Clarsen B, Bahr R, Heymans $M$, et al. The prevalence and impact of overuse injuries in five Norwegian sports: application of a new surveillance method. Scand I Med Sci Sports 2014. doi:10.1111/sms.12223

16 Walker $\mathrm{H}$, Gabbe B, Wajswelner $\mathrm{H}$, et al. Shoulder pain in swimmers: a 12-month prospective cohort study of incidence and risk factors. Physical Therapy Sport 2012;13:243-9.

17 Wolf $B$, Ebinger A, Lawler $M$, et al. Injury patterns in division I collegiate swimming Am I Sports Med 2009;37:2037-42.

18 Junge A, Dvorak J. Influence of definition and data collection on the incidence of injuries in football. Am J Sports Med 2000;28:S40-6.

19 Bjørneboe J, Flørenes $\mathrm{T}$, Bahr $\mathrm{R}$, et al. Injury surveillance in male professional football; is medical staff reporting complete and accurate? Scand I Med Sci Sports 2011;21:713-20

20 Engebretsen L, Steffen K, Alonso JM, et al. Injuries and illnesses during the Winter Olympic Games 2010. Br J Sports Med 2010;44:772-80.

21 Wanivenhaus F, Fox A, Chaudhury S, et al. Epidemiology of injuries and prevention strategies in competitive swimmers. Sports Health 2012;4:246-51.

22 Webster M, Morris M, Galna B. Shoulder pain in water polo: a systematic review of the literature. J Sci Med Sport 2009;12:3-11.

23 Gaunt T, Maffulli N. Soothing suffering swimmers: a systematic review of the epidemiology, diagnosis, treatment and rehabilitation of musculoskeletal injuries in competitive swimmers. Br Med Bull 2012;103:45-88.

24 Johnson J, Sim F, Scott S. Musculoskeletal injuries in competitive swimmers. Mayo Clin Proc 1987;62:289-304.

25 Folland J, Archer G. Shoulder injuries in highly trained competitive swimmers. $\mathrm{Br} J$ Sports Med 2014;48:593. 


\section{Original article}

26 Hibberd E, Myers J. Practice habits and attitudes and behaviors concerning shoulder pain in high school competitive club swimmers. Clin J Sport Med 2013;23:450-5.

27 Ryynänen J, Junge A, Dvorak J, et al. Foul play is associated with injury incidence: an epidemiological study of three FIFA World Cups (2002-2010). Br J Sports Med 2013:47:986-91.

28 Ryynänen J1, Dvorak J, Peterson L, et al. Increased risk of injury following red and yellow cards, injuries and goals in FIFA World Cups. Br J Sports Med 2013;47:970-3.

29 Andersen T, Engebretsen L, Bahr R. Rule violations as a cause of injuries in male Norwegian professional football: are the referees doing their job? Am J Sports Med 2004;32(1 Suppl):62S-8S.

30 Fuller $C$, Junge A, Dvorak J. An assessment of football referees' decisions in incidents leading to player injuries. Am J Sports Med 2004;32(1 Suppl):17S-22S.

31 Comstock R, Fields $\mathrm{S}$. The fair sex? Foul play among female rugby players. I Sci Med Sport 2005;8:101-10.
32 Bjørneboe J, Bahr R, Dvorak J, et al. Lower incidence of arm-to-head contact incidents with stricter interpretation of the Laws of the Game in Norwegian male professional football. Br J Sports Med 2013;47:508-14.

33 Edouard P, Depiesse F, Branco P, et al. Analyses of Helsinki 2012 European Athletics Championships Injury and Illness Surveillance to Discuss Elite Athletes Risk Factors. Clin J Sport Med 2014;24:409-15.

34 Edouard $\mathrm{P}$, Depiesse F, Hertert $\mathrm{P}$, et al. Injuries and illnesses during the 2011 Paris European Athletics Indoor Championships. Scand J Med Sci Sports 2013;23:e213-18.

35 Alonso JM, Edouard P, Fischetto $G$, et al. Determination of future prevention strategies in elite track and field: analysis of Daegu 2011 IAAF Championships injuries and illnesses surveillance. Br J Sports Med 2012;46:505-14.

36 Alonso JM, Tscholl PM, Engebretsen L, et al. Occurrence of injuries and illnesses during the 2009 IAAF World Athletics Championships. Br J Sports Med 2010;44:1100-5.

37 Hanstad D, Rønsen O, Andersen S, et al. Fit for the fight? Illnesses in the Norwegian team in the Vancouver Olympic Games. Br J Sports Med 2011;45:571-5 